\title{
Non-invasive Imaging of Human Embryonic Stem Cells Derived Endothelial Cells Using Reporter Genes
}

\author{
Yizhou Zheng1, Deling Kong' ${ }^{2}$ and Zongjin $\mathrm{Li}^{2,3}$ \\ ${ }^{1}$ State Key Lab of Experimental Hematology, Institute of Hematology E Hospital of Blood \\ Diseases, Chinese Academy of Medical Sciences, Tianjin, \\ ${ }^{2}$ The Key Laboratory of Bioactive Materials, Ministry of Education, Nankai University, \\ the College of Life Science, Tianjin, \\ ${ }^{3}$ Department of Pathophysiology, Nankai University School of Medicine, Tianjin
}

China

\section{Introduction}

Human embryonic stem (hES) cells are pluripotent stem cells capable of self-renewal and differentiation into virtually all cell types (Thomson et al., 1998, Reubinoff et al., 2000). Thus, they hold tremendous potential as cell sources for regenerative therapies. Using endothelial cells for therapeutic angiogenesis/vasculogenesis of ischemia diseases has led to exploring hES cells as a potential source for endothelial progenitor cells. Due to the limitation pluripotency of hES cells, hES cells derived endothelial cells are advantageous when compared with other endothelial cell origin (Li et al., 2007, Li et al., 2009b). Understanding the in vivo behavior of transplanted cells requires novel imaging techniques to longitudinally monitor hES cells localization, proliferation, differentiation, and viability. Molecular imaging has given investigators a high-throughput, inexpensive, and sensitive means for tracking in vivo cell proliferation over times (Li et al., 2009a). This advancement has significantly increased the understanding of the spatiotemporal kinetics of hES cells engraftment in living animals and greatly expedited basic research prior to future clinical translation.

In this chapter, the specific methods needed for tracking hES cells proliferation with bioluminescence imaging and in vitro endothelial differentiation of hES cells will be described. We first established stable hES cell line constitutively expressing double fusion reporter genes (enhanced green fluorescent protein and firefly luciferase) using lentiviral transduction ( $\mathrm{Li}$ et al., 2009b). Unlike other methods of cell tracking, reporter genes are inherited genetically and can be used to monitor cell proliferation and survival of transplanted cells and daughter cells. Next, we introduced two-step procedures to increase endothelial differentiation efficiency of hES cells by subcultured embryoid bodies (EBs) in collagen. Using whole genome microarrays, we investigated the hES cells derived endothelial cells (hES-ECs) transcriptome that occur among sequenced hES cells differentiation processes and human umbilical vein endothelial cells (HUVECs). By intravital microscope, we demonstrated that hES-ECs can form function vessels with blood flow. To monitor cell survive and therapeutic potential of hES-ECs for ischemia diseases, we 
then employed bioluminescence imaging techniques that allow noninvasive monitoring of transplanted hES-ECs engraftment.

\section{Molecular imaging methods for stem cell therapy}

For stem cell research to make the next quantum leap, it is imperative to understand the dynamic processes of hES cells homing, migration, biodistribution, proliferation, and differentiation in the same subject over time. The development of noninvasive imaging techniques is essential for conducting detailed preclinical studies to optimize the delivery methods and strategies that can enhance cell survival. A number of methods are available to track stem cells by molecular imaging. In general, there are two methods to label the cells: (1) direct labeling method, which physically introduce marker(s) into the cells before transplant; (2) indirect labeling method, which genetically introduce reporter gene(s) into the cells before transplant (Wu et al., 2004).

\subsection{Direct labeling methods}

For direct labeling, detectable probes can be loaded into or attached to the cells during tracking. Examples include labeling with super paramagnetic iron oxide (SPIO) for magnetic resonance (MR) imaging, 18F-fluoro-deoxy-glucose ([18F]-FDG) for positron emission tomography (PET) imaging, [111In] oxine for single-photon emission computerized tomography (SPECT), and quantum dots for fluorescence imaging. These techniques have been used for adult and embryonic stem cell imaging (Zhang et al., 2007). Although direct labeling can be used to evaluate the initial deposition of implanted stem cells, the imaging signals tend to diminish with cell division and proliferation or become undetectable after the decay of radioactive tracers. Another confounding factor with this type of labeling and imaging is that non-viable cells may still generate a robust MR signal, as shown in a recent study comparing iron labeling imaging (direct) versus reporter gene imaging (indirect)(Li et al., 2008).

\subsection{Indirect labeling methods}

Indirect imaging such as the reporter gene approach involves inserting reporter gene(s) into stem cells for the purpose of tracking. Products of reporter gene expression generally can be divided into 3 categories: enzyme-based (e.g., herpes simple virus type 1 thymidine kinase [HSV1-tk] or firefly luciferase [Fluc]), receptor-based (e.g., dopamine type 2 receptor [D2R]), and transporter-based (e.g., sodium-iodide symporter [NIS]). Stable transfection or transduction with reporter genes is useful in assessing kinetic survival status of the implanted cells because the reporter genes can be expressed as long as the cells are alive; the inserted reporter gene(s) can be passed on to daughter cells upon cell division. However, a major disadvantage for future clinical applications of reporter gene approach in cell tracking is the requirement for genetic manipulations of the cells, which may lead to insertional mutagenesis. Thus, the recent advances in site-specific chromosomal integration mediated by phiC 31 integrase may become a useful tool to overcome this obstacle (Thyagarajan et al., 2008).

\section{Endothelial differentiation of hES cells}

Due to the limitation of postnatal cell sources and expanding efficiency, endothelial differentiation of hES cells provide an alternative source to generate a large supply of healthy, functional cells. hES-ECs can be generated by two main approaches, spontaneous 
differentiation of embryoid bodies (EBs), also called 3-dimensional differentiation (3D), and 2-dimensional differentiation (2D) (Wang et al., 2007, Yamahara et al., 2008, Kaufman et al., 2001).

For the 3D differentiation, hES cells need to be cultured in low attachment dish for 9-13 days(Levenberg et al., 2002, Li et al., 2008, Wang et al., 2007). Different mediums have been used with or without growth factors. Whole-mount immunostaining CD31 confirmed that hES cells cultivated as EBs spontaneously differentiated into endothelial cells and formed blood vessel like structure(Levenberg et al., 2002, Li et al., 2008). Subsequently, EBs were digested into single cells. Differentiated endothelial cells or hemangioblasts were sorted by fluorescence-ctivated cell sorting (FACS) or magnetic-activated cell separation (MACS). For the 2D differentiation, hES cells were cultured on various mouse fibroblast feeder layers, including mouse embryo fibroblasts (MEF) (Wang et al., 2007), OP9 (Yamahara et al., 2008, Vodyanik et al., 2005), S17 (Kaufman et al., 2001, Vodyanik et al., 2005), MS-5 (Vodyanik et al., 2005), or mouse endothelial cells (Kaufman et al., 2001). hES cells also can be cultured on collagen IV-coated plates for endothelial differentiation (Gerecht-Nir et al., 2003).

Both in vitro assays and in vivo transplantation have been used to characterize the hES derived endothelial cells. After in vitro subculturing, these cells express CD31, CD34, Flk-1, VE-cadherin and vWF. They are capable of DiI-ac-LDL uptake and can generate tube-like structure formation on Matrigel. For in vivo assay, hES-ECs can form a tube-like structure within Matrigel plug. Interestingly, postnatal hemangioblast cell markers such as KDR and CD133 are robustly expressed in undifferentiated hES cells (Chen et al., 2007, Li et al., 2008) and thus are not good markers for endothelial selection of hES cells differentiation.

A major challenge of hES-based therapy is the generation of sufficient numbers of differentiated endothelial cells. The efficiency of endothelial differentiation of the 3D EB system is typically low, ranging from 1\%-3\% (Levenberg et al., 2002, Li et al., 2008). Moreover, it is difficult to get single cells from EBs by enzyme digestion as cell viability is low after this harsh digestion step. Several investigators have introduced modified approaches to bypass the 3D EB formation or serial differentiation procedures to increase differentiation efficiency (Cho et al., 2007, Lu et al., 2007). Wang et al. demonstrated that $\sim 10 \%$ CD34+ progenitor cells are present by monolayer culturing of hES cells on MEF for 10 days (Wang et al., 2007).

To optimize hES cells differentiation to endothelial lineage, we designed a staged protocol that involved EB formation (stage 1) and expansion of endothelial lineage by subcultured EB in collagen (stage 2).

\subsection{Maintenance and differentiation of human embryonic stem cells}

Undifferentiated hES cells (H9 line from Wicell, passages 35 to 45) were grown on an inactivated mouse embryonic fibroblast (MEF) feeder layer as previously described (Chen et al., 2007, Efroni et al., 2008). Briefly, the cell was maintained at an undifferentiated stage on irradiated low-passage MEF feeder layers on $0.1 \%$ gelatin-coated plates. The medium was changed daily. The medium consisted of Dulbecco's modified Eagle's medium (DMEM)/F12, 20\% knockout serum replacement, $0.1 \mathrm{mM}$ nonessential amino acids, $2 \mathrm{mM}$ L-glutamine, $0.1 \mathrm{mM} \beta$-mercaptoethanol, and $4 \mathrm{ng} / \mathrm{ml} \mathrm{rhFGF}-2$ (R\&D Systems Inc., Minneapolis). The undifferentiated hES cells were treated by $1 \mathrm{mg} / \mathrm{ml}$ collagenase type IV in DMEM/F12 and scraped mechanically on the day of passage. To deplete feeder cells before endothelial differentiation, hES cells were cultured on Matrigel coated plates with mTeSR ${ }^{\mathrm{TM}} 1$ medium (Stem Cell Technologies Inc, Vancouver, Canada). 


\subsection{Two-step In vitro differentiation of hES cells}

To induce hES cell differentiation, undifferentiated hES cells were cultured in differentiation medium containing Iscove's modified Dulbecco's medium (IMDM) and 15\% defined fetal bovine serum (FBS) (Hyclone, Logan, UT), 1XBIT (BSA, insulin, transferring; Stem Cell Technologies), $0.1 \mathrm{mM}$ nonessential amino acids, $2 \mathrm{mM}$ L-glutamine, $450 \mu \mathrm{M}$ monothioglycerol (Sigma, St. Louis, MO), $50 \mathrm{U} / \mathrm{ml}$ penicillin, and $50 \mu \mathrm{g} / \mathrm{ml}$ streptomycin, with 20ng/ml bFGF (R\&D Systems Inc., Minneapolis) and 50ng/ml VEGF (R\&D Systems Inc.), either in ultra-low attachment plates for the formation of suspended embryoid bodies (EBs) as previously described (Chen et al., 2007, Levenberg et al., 2002, Li et al., 2008). Briefly, hES cells cultured on Matrigel coated plate with mTeSR ${ }^{\mathrm{TM}} 1$ medium were treated by 2 $\mathrm{mg} / \mathrm{ml}$ dispase (Invitrogen, Carlsbad, CA) for 15 minutes at $37^{\circ} \mathrm{C}$ to loosen the colonies. The colonies were then scraped off, and transferred into ultra low-attachment plates (Corning Incorporated, Corning, NY) for EB formation. EB sprouting differentiation in collagen type I was performed as described(Li et al., 2005), with minor modifications. Briefly, 12 days-old EBs were harvested, and then suspended into rat tail collagen type I (Becton Dickinson, San Jose, CA) at a final concentration of $1.5 \mathrm{mg} / \mathrm{ml}$ collagen. After thoroughly mixing EBs into collagen, $1.5 \mathrm{ml} /$ well of mixture were added into six-well-plate. The plates were incubated at $37^{\circ} \mathrm{C}$ for $30 \mathrm{~min}$, allowing gel polymerization prior to addition of medium. After gel formation, each dish was supplemented with EGM-2 medium (Lonza, Basel, Switzerland) with 50ng/ml VEGF additional. The cultures were then incubated for 3 days without media change (Figure 1).

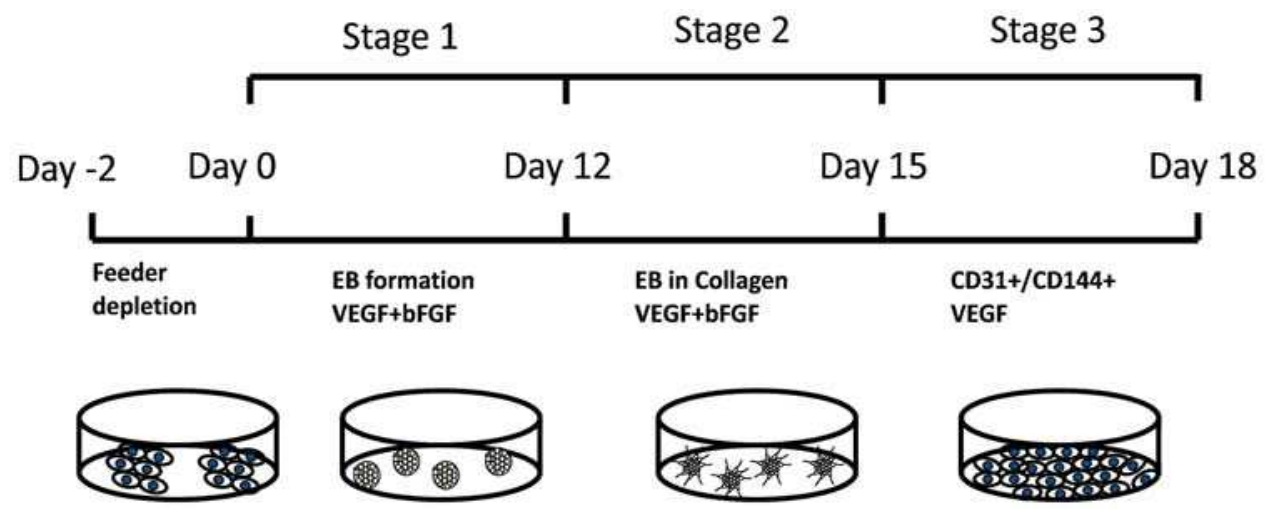

Fig. 1. Specification of the endothelial lineage differentiation from hES cells. An outline of the protocol used for the differentiation of hES cells to the endothelial lineage.

Undifferentiated hES cells were grown to $60 \%-70 \%$ confluence on Matrigel and subcultured in low attachment dish with differentiation medium supplement VEGF and bFGF, dated as day 0 . At day 12 , hEBs were collected and digested and CD31 ${ }^{+} / \mathrm{CD} 144^{+}$cells were isolated by FACS and sub-cultured in EGM-2 medium to expand and induce endothelial maturation

After embedded into collagen, EBs rapidly developed into vascular sprouting in the presence of growth factors within 3-4 days. Whole-mount immunostaining confirmed that $\mathrm{CD} 1^{+}$and $\mathrm{CD} 144^{+}$cells were organized into channel-like structures within day-12 EBs (Figure 2A). These data demonstrate that some cells within EBs can spontaneously differentiate into endothelial cells that are then able to form blood vessel-like structures, confirming previous reports from our lab and others (Levenberg et al., 2002, Li et al., 2008, 
Wang et al., 2007). CD31/CD144 expression increased swiftly to $10-15 \%$ after subculture in collagen as confirmed by FACS analysis, as compared to $1-2 \%$ using the conventional EB culturing technique (Figure 2B). After sorting, CD31 $/ \mathrm{CD} 144^{+}$cells were further expanded as a nearly pure population $(98 \%)$ and these cells were used for subsequent experiments.

A
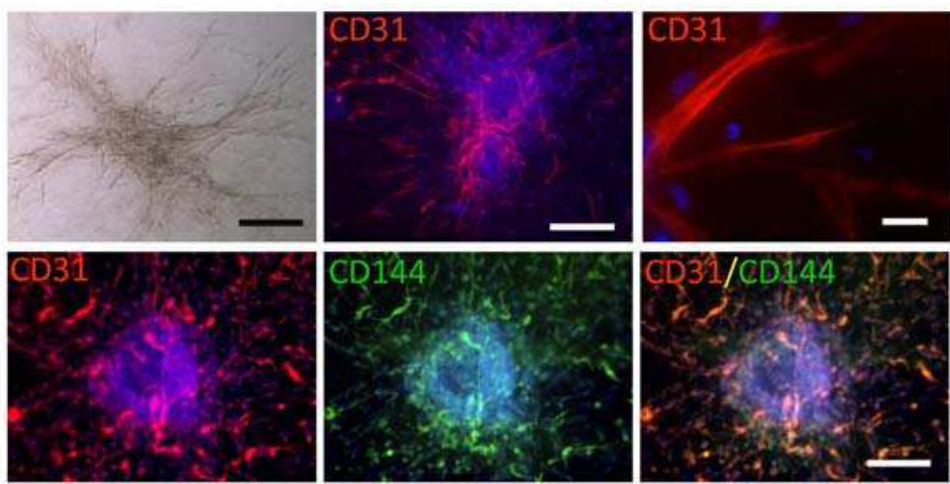

B

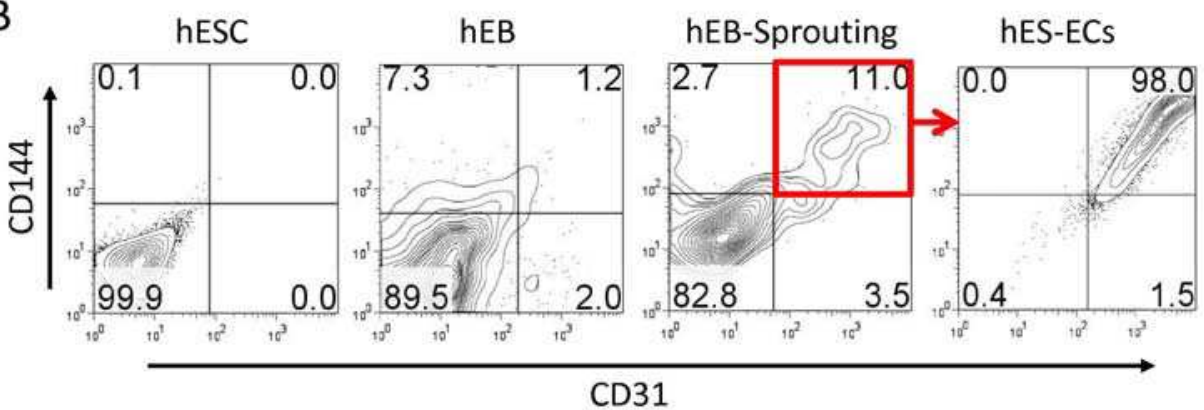

Fig. 2. Specification of the endothelial lineage differentiation from hES cells. (A) Endothelial differentiation of sprouting hEBs in collagen. Representative sprouting hEBs after cultured 3 days in collagen matrix (upper panel, left). Whole-mount immunostaining showed CD31 sprouting with channel-like vessel structures and CD31 cell clumps (upper panel). Also, those sproutings are CD31 and CD144 double positive. (B) Kinetic expression of CD31 and CD144 during two-step hES cells differentiation procedures. hES-ECs were enriched by $\mathrm{CD} 31^{+} / \mathrm{CD} 144^{+}$isolation (right panel)

\subsection{Flow cytometry sorting (FCS) of hES-ECs}

Single cell suspension from hEB-sprouting was obtained by treatment with $0.25 \%$ collagenase I (Invitrogen, Carlsbad, CA) at $37^{\circ} \mathrm{C}$ for $20-30 \mathrm{~min}$, then with $0.56 \mathrm{units} / \mathrm{ml}$ Liberase Blendzyme IV (Roche Diagnostics, Indianapolis) at $37^{\circ} \mathrm{C}$ for $10-20$ minutes. Cells were passed through a 40- $\mu \mathrm{m}$ cell strainer (BD Falcon, San Diego) (Xu et al., 2006). Cells were incubated with mouse anti-human CD31 (BD) and CD144 (Abcam, Cambridge, MA). The CD31 ${ }^{+} / \mathrm{CD} 144^{+}$cells were isolated using FACScan (Becton Dickinson). To generate hESECs, the isolated CD31+ CD144+ cells from hEB-sprouting were grown on $4 \mu \mathrm{g} / \mathrm{cm}^{2}$ human fibronectin (Calbiochem, San Diego, CA) coated plates in EGM-2 (Lonza) with additional 5 $\mathrm{ng} / \mathrm{ml}$ VEGF. The medium was changed every 2-3 days. 


\subsection{Biological characteristics of hES-ECs}

Flow cytometry analysis, immunostaining, DiI-ac-LDL uptake assay, and Matrigel assay were used to confirm endothelial cell phenotype within these CD $31^{+} / \mathrm{CD} 144^{+}$purified $\mathrm{hES}$ cells. Antibodies used for flow cytometry analysis were phycoerythrin (PE) conjugated antiCD31, CD34 (BD Pharmingen) and Allophycocyanin (APC) conjugated anti-KDR, CD133 (R\&D Systems), APC conjugated anti-mouse IgG2a, and rabbit anti-human CD144 (Abcam). The stained cells were analyzed using FACS Vantage (Becton-Dickinson, MA). Dead cells stained by propidium-iodide (PI) were excluded from the analysis. Isotype-identical antibodies served as controls (BD Pharmingen).

For immunostaining, the cells were fixed with with $4 \%$ paraformaldehyde in PBS at room temperature for 15 minutes. The fixed cells were permeated by $1 \%$ Triton 100 and incubated with $2 \%$ BSA for 30 minutes to block nonspecific binding, and stained for 1 hour with the primary antibodies: CD31, CD144 (BD Pharmingen) and vWF (Chemicon International Inc), respectively. The cells were then incubated for 30 minutes with either Alexa 593-conjugated donkey anti-mouse secondary antibody or Alexa 488-conjugated donkey anti-rabbit secondary antibody (Invitrogen), and counter stained with DAPI.

For DiI-ac-LDL uptake assay, hES-ECs were incubated with $10 \mu \mathrm{g} / \mathrm{ml}$ of DiI-Ac-LDL (Molecular Probes, Eugene, OR) at $37^{\circ} \mathrm{C}$ for 6 hours. After washing with PBS twice, cells were fixed and counterstained with DAPI (4, 6-diamidino-2-phenylindole) as described (Chen et al., 2007). The formation of endothelial tubes was assessed by seeding cells in 24well plates coated with Matrigel (BD Pharmingen) and incubating them at $37^{\circ}$ for 12 hours as described(Li et al., 2007).

hES-ECs morphologically resembled HUVECs, which were uniformly flat, adherent, and cobblestone-like in appearance. When $\mathrm{CD} 31^{+} / \mathrm{CD} 144^{+}$cells were cultured in endothelial growth medium, the majority of cells were adherent and expressed endothelial markers (CD31, CD144) at the endothelial cell adherent junctions as well as von Willebrand factor (vWF) located within the cytoplasm (Figure 3A). The CD31+/CD144+ cells also uptake DiIacetylated low-density lipoprotein, and rapidly formed vascular network-like structures when placed on Matrigel (Figure 3B). Taken together, these data confirm that these differentiated cells were of endothelial lineage.

A
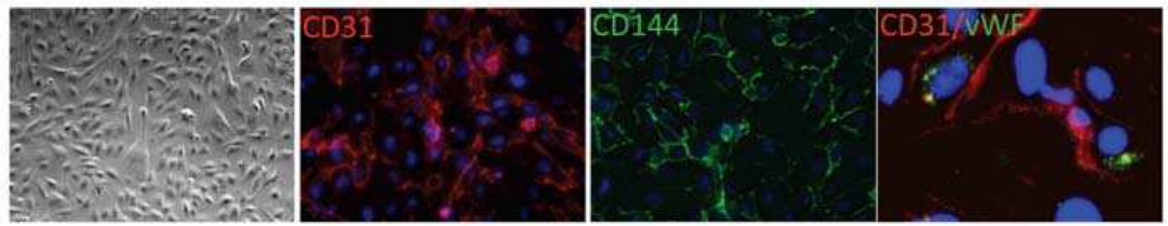

HUVEC

B
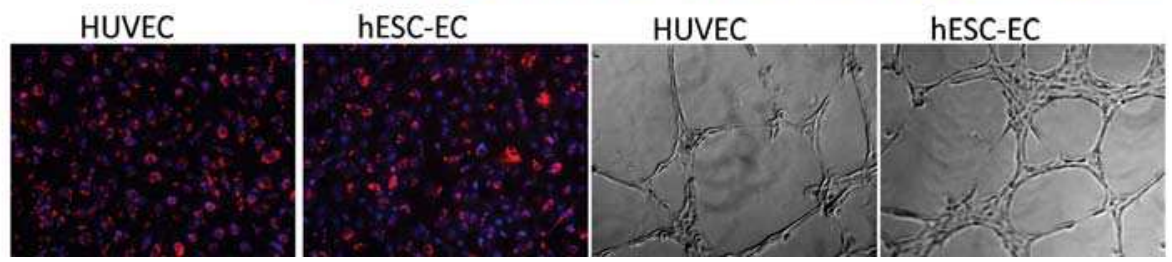

Fig. 3. In vitro characterization of hES-EC. (A) Morphogenesis shows the cells were cobble stone like; histology show CD31 and CD144 express on cell membranes, and vWF in the cytoplasm. (B) Compare to HUVEC, hES-ECs also can uptake ac-DiI-LDL and form tube like structure on Matrigel 


\subsection{Microarray hybridization and data acquisition}

In order to define at a molecular level the changes occurring at each stage of hES cells differentiation to endothelial progeny, and to validate that these cells are similar to human umbilical vein endothelial cells (HUVECs), we also perform transcriptional profiling using whole human genome microarrays and real-time PCR arrays. Total RNA samples were isolated in Trizol (Invitrogen) followed by purification over a Qiagen RNeasy column (Qiagen) from undifferentiated hES cells at day 0, differentiated hEBs at day 12, hES-derived endothelial cells (after CD31/CD144 sort), and human umbilical endothelial cells (HUVEC). Four samples from each group (for a total of 16 unique samples) were harvested for RNA isolation. Using Agilent Low RNA Input Fluorescent Linear Amplification Kits, cDNA was reverse transcribed from each of 16 RNA samples representing four biological quadruplicates, as well as the pooled reference control, and cRNA was then transcribed and fluorescently labeled with Cy5/Cy3. cRNA was purified using an RNeasy kit (Qiagen, Valencia, CA, USA). 825 ng of Cy3- and Cy5- labeled and amplified cRNA was hybridized to Agilent $4 \times 44 \mathrm{~K}$ whole human genome microarrays (G4112F) and processed according to the manufacturer's instructions. The array was scanned using Agilent G2505B DNA microarray scanner. The image files were extracted using Agilent Feature Extraction software version 9.5.1 applying LOWESS background subtraction and dye-normalization.

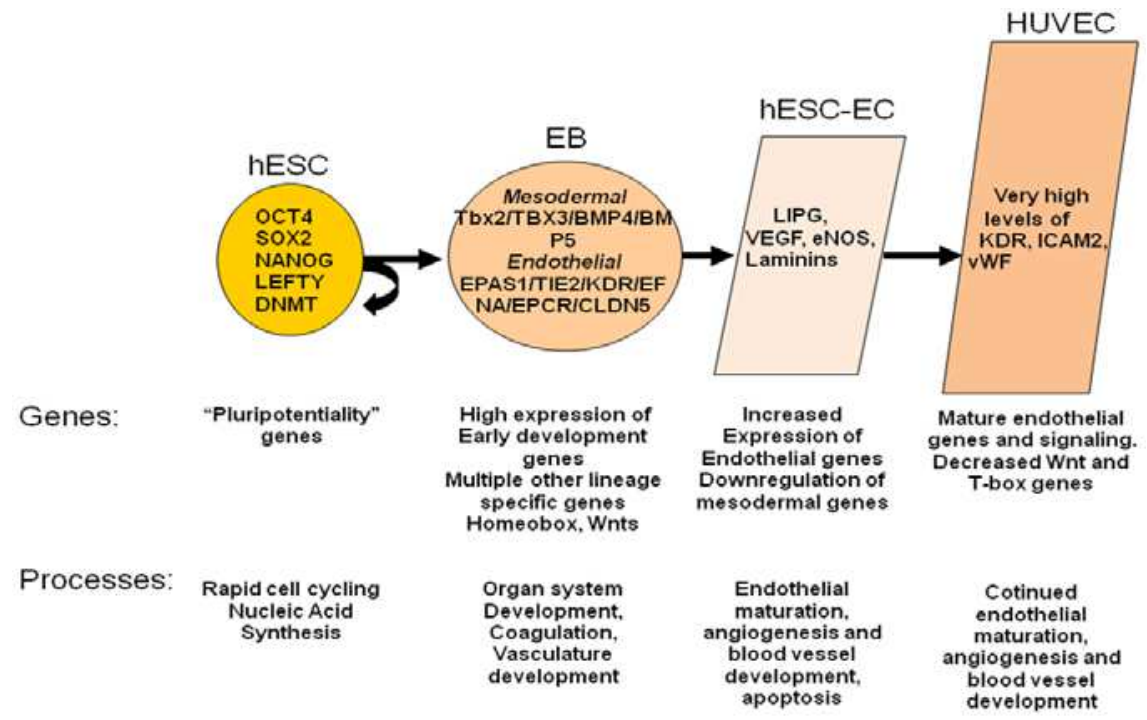

Fig. 4. Major themes in gene expression profiles at each stage of differentiation. (A) hES cells express high levels of pluripotency-associated genes including Oct4, Sox2, NANOG, Lefty, and DNMT. At the EB stage, the cells express high levels of mesodermal master regulators such as Tbx2, and BMP4 as well as very enriched levels of endothelial specific master regulators including EPAS1, TIE2, KDR, and EFNA. This population also expresses genes from other cell layers, and many developmental genes from Wnt and homeobox families. hES-ECs downregulate early mesodermal genes and express more endothelial specific genes, while HUVECs have the highest levels of mature endothelial gene expression with very few other developmental lineages represented 
The resulting data were analyzed using GeneSpring GX 7.3.1 to identify genes which had changed expression significantly between stages. A summary of our major findings is shown in Figure 4. To obtain an overview of the transcriptional landscape, we looked at the data using principal components analysis (PCA), a dimensional reduction technique which identifies "principal components" or major trends in gene expression in the overall data (Figure 5). PCA demonstrates that each of the four replicates from each stage has very similar transcriptional profiles to one another, but distinctly different between stages, as expected.

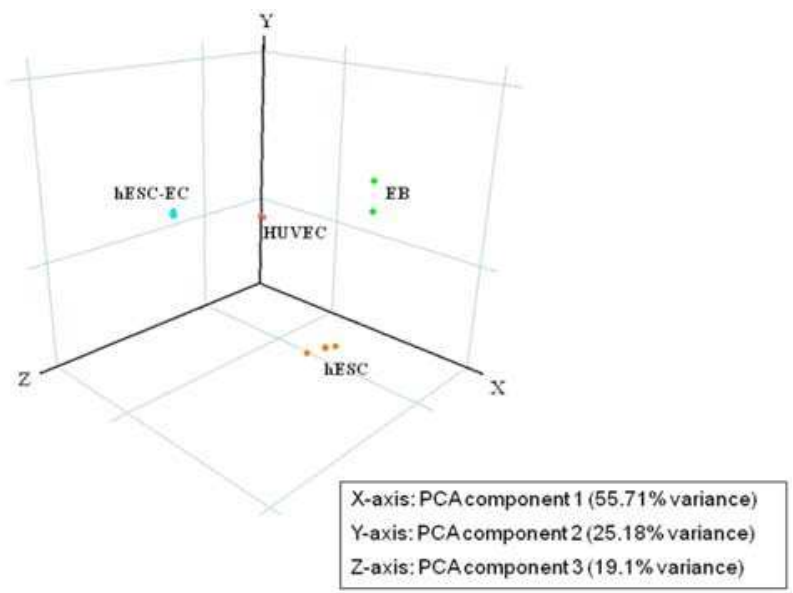

Fig. 5. Principal Components Analysis (PCA) shows that replicate experiments of each cell type are very similar while differentiation groups separate significantly along components 1 and 2

\subsection{Real time RT-PCR (qRT-PCR)}

To investigate changes in endothelial related genes during endothelial cell differentiation in collagen, we performed quantitative real-time PCR analysis using the Human Endothelial Cell Biology PCR array on undifferentiated hES cells, EBs, EB sprouting, and hES-ECs, and on HUVEC as a positive control. qRT-PCR assays were performed using the human endothelial cell biology RT2 Profiler ${ }^{\mathrm{TM}}$ PCR Array (SuperArray Bioscience, Frederick, MD) on an ABI PRISM 7900 HT (Applied Biosystems, Foster City, CA). Data analysis is available at the company website (http://www.superarray.com/pcr/arrayanalysis.php). Briefly, total RNAs were isolated using RNeasy (Qiagen, Waltham, MA) from undifferentiated hES cells at day 0 , differentiated hEBs at day 12, hEB-sprouting, hES-derived endothelial cells (after CD31/CD144 sort), and human umbilical endothelial cells (HUVEC) as positive control. First-strand cDNAs were generated using iScript Select cDNA Synthesis Kit (BioRad, Hercules, CA). For real-time PCR reaction, first-strand cDNAs were added to RT qPCR Master Mix (SuperArray Bioscience). Samples were heated for $10 \mathrm{~min}$ at $95^{\circ} \mathrm{C}$ and then subjected to 40 cycles of denaturation at $95^{\circ} \mathrm{C}$ for $15 \mathrm{sec}$ and annealing and elongation at $60^{\circ} \mathrm{C}$ for $1 \mathrm{~min}$.

Analysis of scatter plot demonstrated 28 genes were upregulated when day-12 EBs were embedded into collagen type I for an additional 3 days (Figure 6A). Analysis of scatter plots also revealed that 30 genes were upregulated and 8 genes downregulated after 
undifferentiated hES cells differentiated into EBs, and 33 genes upregulated and 2 genes downregulated after hES cells differentiated into EB sprouting. Quantitative analysis showed after endothelial induction, ICAM1, CD31, VCAM1, and vWF were significantly upregulated, while FGF1, Flt1, KDR and VEGFA were expressed in undifferentiated cells and upregulated with endothelial differentiation of hES cells (Figure 6B), which were also consistent with the microarray data. To explore the mechanism of promotion of endothelial differentiation in collagen, quantitative analysis was carried out and showed that endothelial cell activation genes were upregulated swiftly and endothelial differentiation was triggered after hEBs were embedded into collagen (Figure 6C).
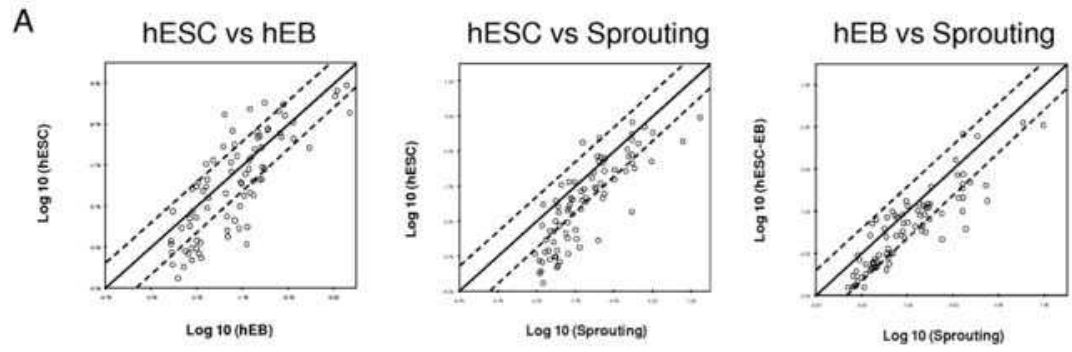

B
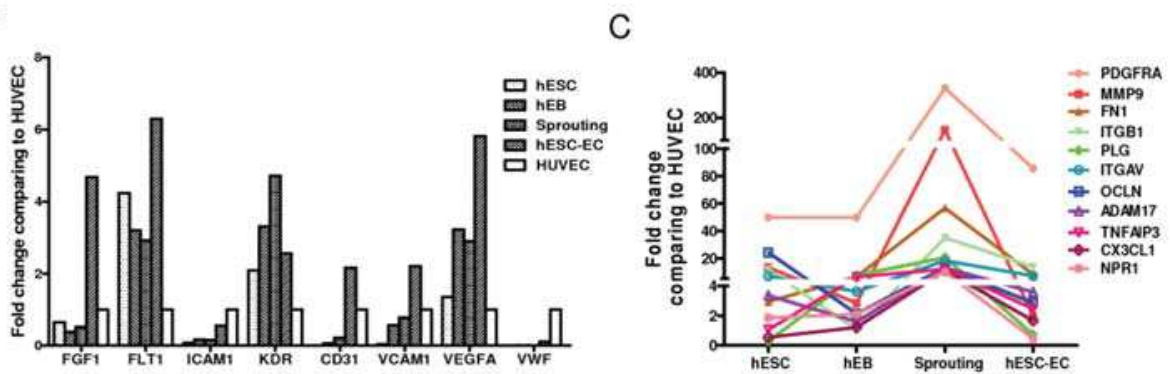

Fig. 6. Quantitative PCR analysis of endothelial gene in hES, hEB, hEB sproutin, hES-EC and HUVEC. (A) Scatter plots of the endothelial related gene-expression were compared between $\mathrm{hES}$ and hEB, hES and sprouting, and hEB and sprouting . Endothelial related genes expression was analyzed by Human Endothelial Cell Biology RT2 Profiler PCR Array. The array includes 84 genes related to endothelial cell biology. The lines indicate the diagonal and 4-fold changes between the two samples. (B) Kinetic expression of selected endothelial gene on hES, hEB, sprouting and hES-EC between HUVEC. Compared to HUVEC, hES-ECs express abundant endothelial gene except adult endothelial gene vWF. (C) Cell matrix related gene increase swiftly in collagen regardless beginning level

\section{Imaging fate of transplanted hES-ECs}

Stem cell therapy is an exciting area of research that promises future treatment of many diseases (Chiu, 2003). However, to fully understand the beneficial effects of stem cell therapy, investigators must be able to track the biology and physiology of transplanted cells in living subjects over time. At present, most cell therapy protocols require histological analysis to 
determine viable engraftment of the transplanted cells. The development of sensitive, noninvasive technologies to monitor this fundamental engraftment parameter will greatly aid clinical implementation of cell therapy. Therefore, to validate the in vivo engraftment potential of our hES-ECs, we performed noninvasive monitoring of transplanted hES-ECs in a murine myocardial ischemia model by bioluminescence imaging (BLI).

Among the different reporter gene imaging techniques, bioluminescence imaging (BLI) is extremely useful because of its high sensitivity, high-throughput screening, and straightforward imaging procedures. Firefly luciferase (Fluc) is a 61-kDa monomeric protein, which reacts with its substrate D-luciferin in the presence of oxygen, $\mathrm{Mg}^{2+}$, and ATP to emit luminescence. The light can be captured by high sensitive CCD camera, such as IVIS imaging system (Caliper Life Sciences, Mountain View, CA). This imaging modality is currently limited to small animal models, because bioluminescence imaging relies on lowenergy photons $(2-3 \mathrm{eV})$ that become attenuated within deep tissues. Recent work demonstrated that hES cells can be stably transduced with a lentiviral vector carrying a novel double-fusion reporter gene that consists of firefly luciferase and enhanced green fluorescence protein (Fluc-eGFP) (Li et al., 2008). Reporter gene expression has shown no significant adverse effects on hES cells viability, proliferation, or differentiation into hESECs. After transplantation into the mouse hindlimb, hES-ECs can be tracked up to 4 week by BLI. Moreover, postmortem histology can be used to confirm engraftment of transplanted hES-ECs based on GFP immunostaining. Finally, the reporter gene approach may also permit longitudinal monitoring of endothelial differentiation process.

\subsection{Lentiviral transduction of hES cells with double fusion (DF) reporter gene}

In order to track transplanted cells in vivo, hES cells were transduced at multiplicity of infection (MOI) of 10 with self-inactivating (SIN) lentiviral vector carrying a human ubiquitin promoter driving firefly luciferase and enhanced green fluorescence protein (FluceGFP) (Figure 7A). Stable clones were isolated using FACS for eGFP expression. Afterwards, Fluc activity within different cell numbers was confirmed ex vivo using Xenogen IVIS 200 system (Xenogen, Alameda, CA) as described (Cao et al., 2006). Nontransduced hES cells (control) and hES cells with DF reporter gene (hES-DF) were stained for Oct-4 (Chemicon, Temecula, CA). The undifferentiated hES cell colonies were fixed in $4 \%$ paraformaldehyde in PBS for 15 minutes. Nonspecific binding was blocked with $4 \%$ normal goat serum for 30 minutes, following which the colonies were stained with antibodies to Oct-4 and incubated with Alexa 594-conjugated rabbit anti-goat secondary antibodies (Invitrogen) for 30 minutes and nuclear counterstained with DAPI. Images were obtained with a Zeiss Axiovert microscopy (Sutter Instrument Co., USA). Subsequently, the processes for in vitro endothelial cell differentiation and characterization were the same as control non-transduced hES cells described earlier.

The efficiency of self-inactivating lentiviral vector for transducing hES cells was $\sim 20 \%$ (data not show). Both control non-transduced hES cells and stably transduced hES cells showed similar expression patterns of stem cell markers Oct-4 on immunostaining, suggesting minimal side effects by reporter gene on maintaining stem cell state (Figure 7B). Upon culturing onto 24-well plates, we also observed a strong correlation $\left(\mathrm{r}^{2}=0.99\right)$ between Fluc activity and cell numbers ex vivo using the Xenogen IVIS system (Figure 7C). The cell proliferation and cell viability data are also similar between control hES cells and transduced hES cells (data not shown). Overall, these data are consistent with our previous 
studies showing minimal effects of reporter genes on mouse ES cell survival, proliferation, and differentiation (Cao et al., 2006, Wu et al., 2006a, Wu et al., 2006b).

A

\begin{tabular}{|l|l|l|l|l|}
\hline $5^{\prime}$ 'LVITR & PUbiquitin & Flue & QGFP & SIN LTR 3' \\
\hline
\end{tabular}

B
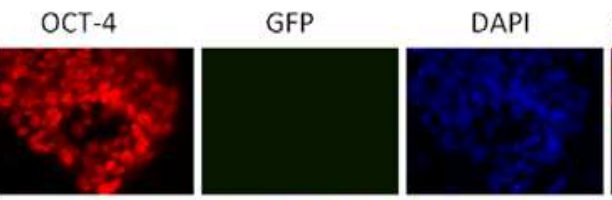

OCT-4/DAPI/GFP

hES-BF
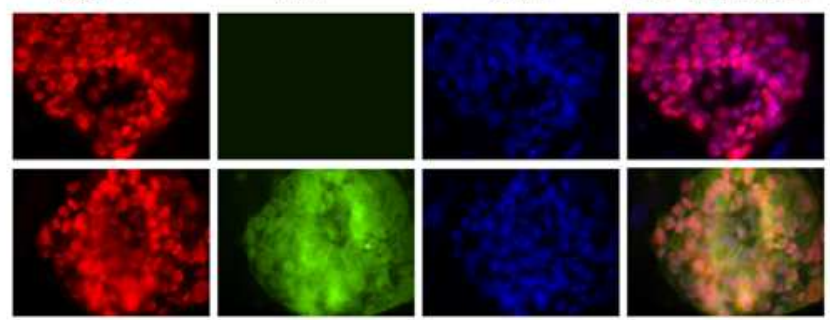

C
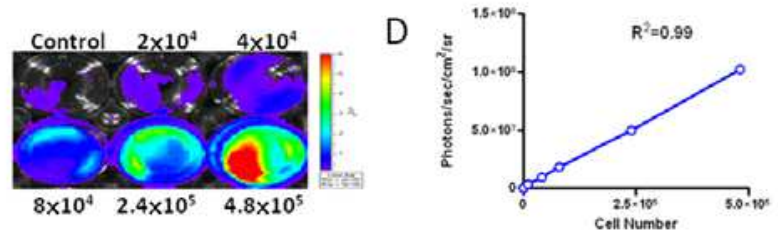

Fig. 7. Stable lentiviral transduction of hES cells with the double fusion reporter genes. (A) Schema of the double fusion reporter gene containing fusion of Fluc-sGFP. The double fusion reporter gene was cloned into a self-inactivating lentiviral vector downstream from the ubiquitin promoter. (B) Control hES cells and transduced hES cells showed similar expression pattern of Oct-4 under fluorescence microscopy. DAPI staining is used as a nuclear marker. (C) Ex vivo imaging analysis of stably transduced cells show increasing bioluminescence signals with cell numbers of hES cells $\left(\mathrm{r}^{2}=0.99\right)$. Data are representative of three independent experiments. Abbreviations: DAPI, 4', 6-diamidino-2-phenylindole

\subsection{Longitudinal bioluminescence imaging of hES cell survival in living animals}

Previous studies have demonstrated that hES-derived cardiomyocyte transplantation can improve cardiac function after myocardial infarction (van Laake et al., 2007, Laflamme et al., 2007). To understand the therapeutic potential of hES-ECs for treatment of ischemia heart disease, we subjected SCID mice to LAD ischemia and reperfusion followed by injection with either $1 \times 10^{6}$ cultured hES-ECs $(n=28)$ or PBS $(n=15)$. For sham operated animals $(n=5)$, open thoracotomy was performed without ligation of the LAD and without injection of hESECs or PBS. All surgical procedures were performed on 8-10 week old female SCID Beige mice (Charles River Laboratories, Wilmington, MA) by a single experienced micro-surgeon. Protocols were approved by the Stanford University Animal Care and Use Committee guidelines. Following induction with inhaled isoflurane ( $2 \%$ to $3 \%)$, mice were intubated and ventilated and anesthesia was maintained with inhaled isoflurane (1\% to $2.5 \%)$. A left thoracotomy was performed followed by ligation of the middle of left anterior descending (LAD) artery for 30 minutes followed by reperfusion. Infarction was visually confirmed by 
blanching of the anterolateral region of the left ventricle along with dyskinesis. After 30 minutes, $1 \times 10^{6} \mathrm{hES}$-ECs were injected intramyocardially into the peri-infarct zone at $20 \mu \mathrm{l}$ of total volume. Control animals received PBS injection instead. For sham operated animals, suturing was performed without ligation. Post-operative analgesia was provided by a onetime, subcutaneous injection of buprenorphine $(0.1 \mathrm{mg} / \mathrm{kg}$ body weight). Animals were recovered in a warmed, humidified chamber.

Cardiac bioluminescence imaging was performed using the Xenogen IVIS 200 system. After intraperitoneal injection of the reporter probe D-Luciferin ( $150 \mathrm{mg}$ luciferin $/ \mathrm{kg})$, animals were imaged for 1-10 minutes. The same mice were imaged for up to 8 weeks. Bioluminescence signal was quantified in units of maximum photons per second per $\mathrm{cm}$ square per steridian (photons $/ \mathrm{sec} / \mathrm{cm}^{2} / \mathrm{sr}$ ). Injection of hES-ECs into infarcted myocardium resulted in a robust bioluminescence signal at day 2 . However, serial imaging of the same animals out to 8 weeks demonstrated a significant decay in bioluminescence, suggesting acute donor cell death. When normalized to the signal on day 2 after injection, the percent bioluminescence signals were $36.8 \pm 15.5$ at day $4,6.7 \pm 1.5$ at day $7,3.5 \pm 0.6$ at day $14,2.3 \pm 0.5$ at day 28 , and $0.8 \pm 0.4$ at day 56 (Figure 8 ). Thus, we believe less than $1 \%$ of transplanted hESECs survived beyond 8 weeks.
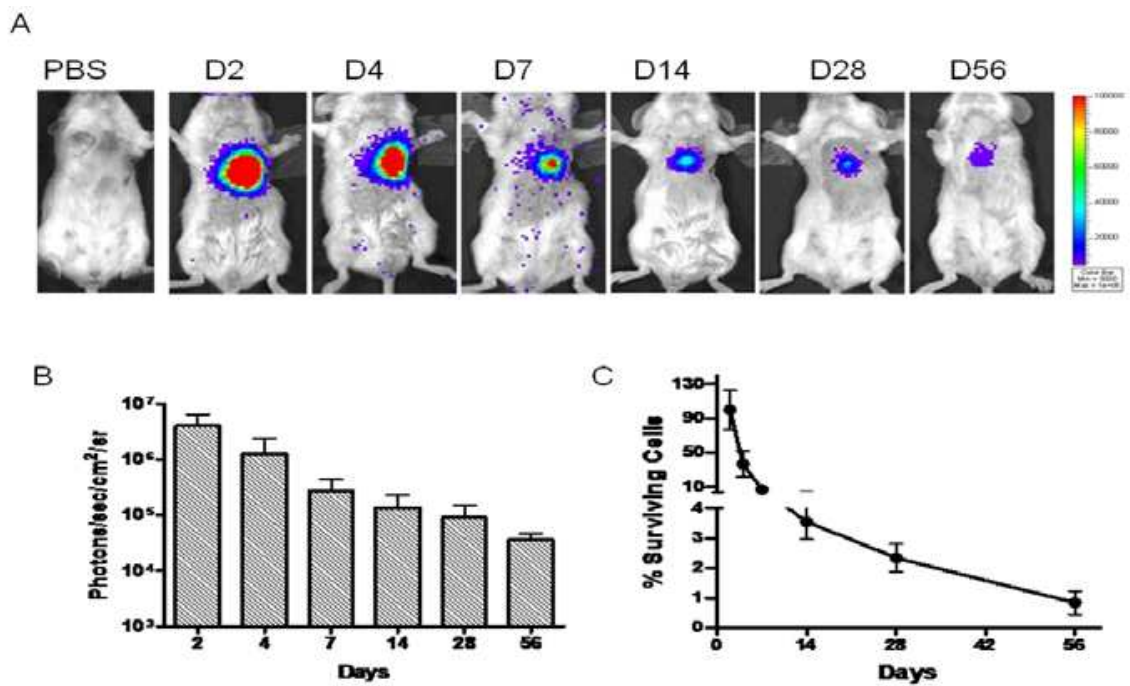

Fig. 8. Molecular imaging of hES-EC fate after transplantation. (A) A representative animal injected with $1 \times 10^{6}$ hES-ECs shows significant bioluminescence activity at day 2, which decreases progressively over the following 8 weeks. A representative control animal injected with PBS shows no imaging signals as expected. (B) Detailed quantitative analysis of signals from all animals $(n=28)$ transplanted with hES-ECs (signal activity is expressed as photons $/ \mathrm{sec} / \mathrm{cm}^{2} / \mathrm{sr}$ ). (C) Donor cell survival plotted as \% signal activity from day 2 to week 8

\subsection{Assessment of cardiac viability following hES-EC based therapy by PET imaging} Small animal PET imaging was carried out at day -7 (baseline) and days 2, 14, 28, and 56, post-operatively. Mice were fasted for 3 hours prior to radioisotope injection and then were 
injected with $140 \pm 17 \mu \mathrm{Ci}$ of [18F]-FDG via the tail vein. At 45 to 60 minutes post-injection, animals were anesthetized with inhaled $2 \%$ isoflurane and imaged with a Vista microPET system (GE Health Care). Images were reconstructed by filtered back projection (FBP) and analyzed by image software Amide (http://amide.sourceforge.net/index.html). Threedimensional regions of interest (ROIs) were drawn encompassing the heart. Counts/pixel/min were converted to counts $/ \mathrm{ml} / \mathrm{min}$ (assuming a tissue density of $1 \mathrm{~g} / \mathrm{ml}$ ) with a calibration constant derived from scanning a cylindrical phantom (Toyama et al., 2004). For each ROI, counts $/ \mathrm{ml} / \mathrm{min}$ were then converted to counts/gram/min and divided by the injected dose to obtain the image ROI-derived [18F]-FDG percentage injected dose per gram of heart (\% ID/g). To measure the myocardium infarction size, [18F]-FDG PET images were assembled into polar maps (Kudo et al., 2002). The size of perfusion defects was measured as the myocardium with $50 \%$ of maximum activity and expressed as percent total myocardium polar map by GE Healthcare Advantage Workstation (GE Healthcare, UK). Myocardial metabolic activity and perfusion defect imaging can be detected using a microPET system and 18F-fluorodeoxyglucose ([18F]-FDG) radiotracer (Kudo et al., 2002). This technique can be used to accurately detect changes in cardiac viability following

A

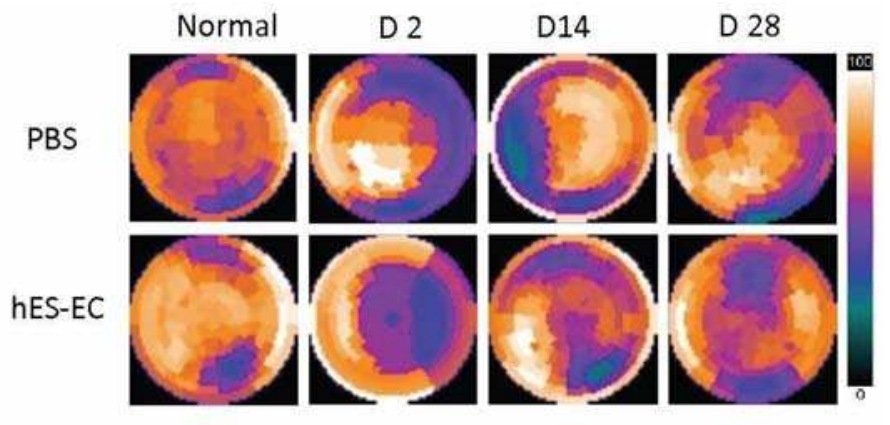

B

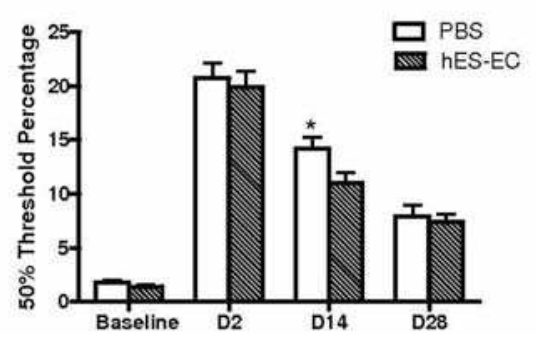

Fig. 9. [18F]-FDG PET imaging of cardiac viability. (A) Representative polar map of the microPET images obtained from mice treated with PBS vs. hES-ECs. (B) Measurements are based on $50 \%$ thresholds. ${ }^{*} P<0.05$ vs. PBS group at day 14

infarctions in small animal models (Schelbert et al., 2003). Therefore, we performed $\left[{ }^{18} \mathrm{~F}\right]-$ FDG PET scans at baseline, day 2, day 14, day 28, and day 56 post infarction for hES-EC treated and control animals. We observed a significant reduction in cardiac [ $\left.{ }^{18} \mathrm{~F}\right]-\mathrm{FDG}$ uptake for both groups at day 2, confirming successful myocardial infarction. At day 14, 
there was a significant increase in cardiac viability (indicated by increased [18F]-FDG uptake) in the hES-EC treated group compared to controls $(26.3 \pm 1.8$ vs. $22.4 \pm 3.4 ; P<0.05)$. Analysis of the $\left[{ }^{18} \mathrm{~F}\right]-\mathrm{FDG}$ PET images using polar-map reconstruction revealed reduced infarction size on the hES-EC transplantation group compared to the PBS group, but there was no significant difference at any day other than day 14 (Figure 9). Overall, the trends for changes in functional contractility and metabolic activity were very similar based on the microPET imaging results.

\subsection{Histologic assessment of hES-ECs engraftment}

Histologic analysis of the myocardium was performed by examining thin sections of the gross specimen and via immunofluorescent microscopic examination. Microscopic examination showed the presence of GFP positive cells within myocardium (Figure 10). At day 4, clumps of hES-ECs can be found in the interstitial spaces between cardiomyocytes, as seen with $\alpha$-sarcomeric actin ( $\alpha$-SA) and GFP double staining (Figure 10A). At day 28, GFP, $\alpha-S A$, and mouse-specific CD31 triple staining revealed hES-ECs that had formed microvessel structures and integrated with host vasculature. However, the overall frequency of GFP+ cells was significantly decreased at day 28 (Figure 10B, C), which is consistent with the decrease in bioluminescence signals measured over this same period of time and likely due to massive cell death. Moreover, immunostaining with mouse CD31 and $\alpha$-SA at day 4
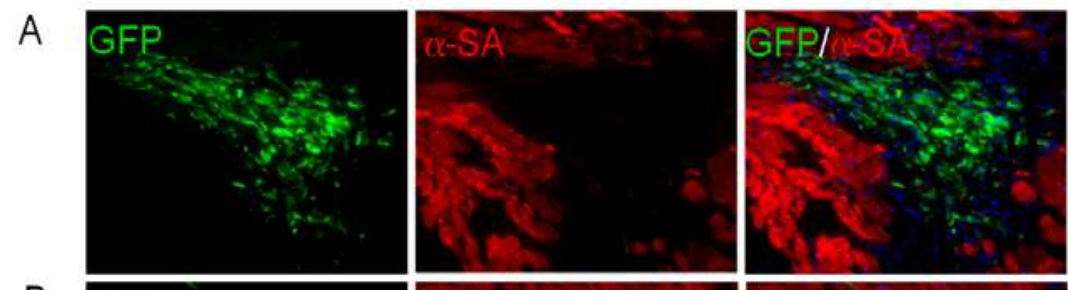

B
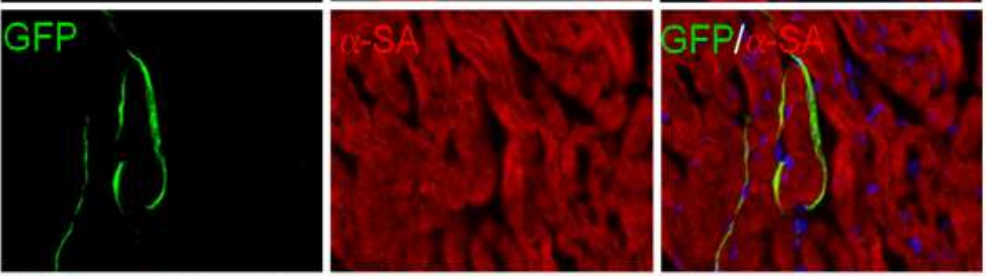

C
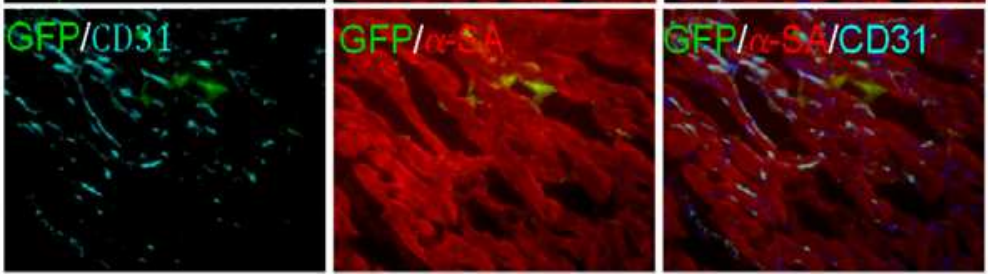

Fig. 10. Confirmation of engrafted hES-ECs by immunofluorescence. (A) hES-ECs within the recipient myocardium 4 days after injection showed clump formation. (B, C) At day 28, transplanted hES-ECs can differentiate into vasculature and integrate with host myocardium as confirmed by GFP, mouse CD31, and $\alpha$-sarcomeric actin ( $\alpha$-SA) co-staining. However, this population became significantly rare compared to day 4 
showed no host vasculature extension into the hES-EC clumps (data not shown), which suggests no direct nutrient transport to transplanted cells other than diffusion. Finally, examination of the explanted hearts showed a downward trend in infarct size and an upward trend in microvascular density (MVD) in the hES-EC treated group, though these differences with controls were not statistically significant (data not shown).

\subsection{Functional imaging with intravital microscope}

To understand whether hES-ECs also possess vasculogenic ability in vivo, we next evaluated the in vivo vascular formation potential of hES-ECs after transplantation in the model of mouse dorsal window chamber. Previous data showed that supporting fibroblast cells were needed to stabilize engineered blood vessels (Au et al., 2008, Wang et al., 2007). However, there are obvious drawbacks in using mouse support cells in study of vessel maturation of human cell. In this study, we introduced collagen type I and Matrigel, without support cells, and showed hES-ECs can form functional vasculature and are stable up to 2 months post transplantation. Briefly, one million hES-ECs were suspended in $1 \mathrm{ml}$ solution of rat-tail type I collagen (at final concentration $1.5 \mathrm{mg} / \mathrm{ml}$ ) (BD) and Matrigel (BD) (1:1) at $4^{\circ} \mathrm{C}$. The cell suspension was pipetted into 12 -well plates and warmed to $37^{\circ} \mathrm{C}$ for 30 minutes to allow polymerization of collagen and Matrigel and $1 \mathrm{ml}$ EGM-2 medium was added after that (Figure 11A). After one day of culture in $5 \% \mathrm{CO}_{2}$, a skin puncher was applied to create circular disk-shape pieces of the construct (8-mm diameter), and they were implanted into
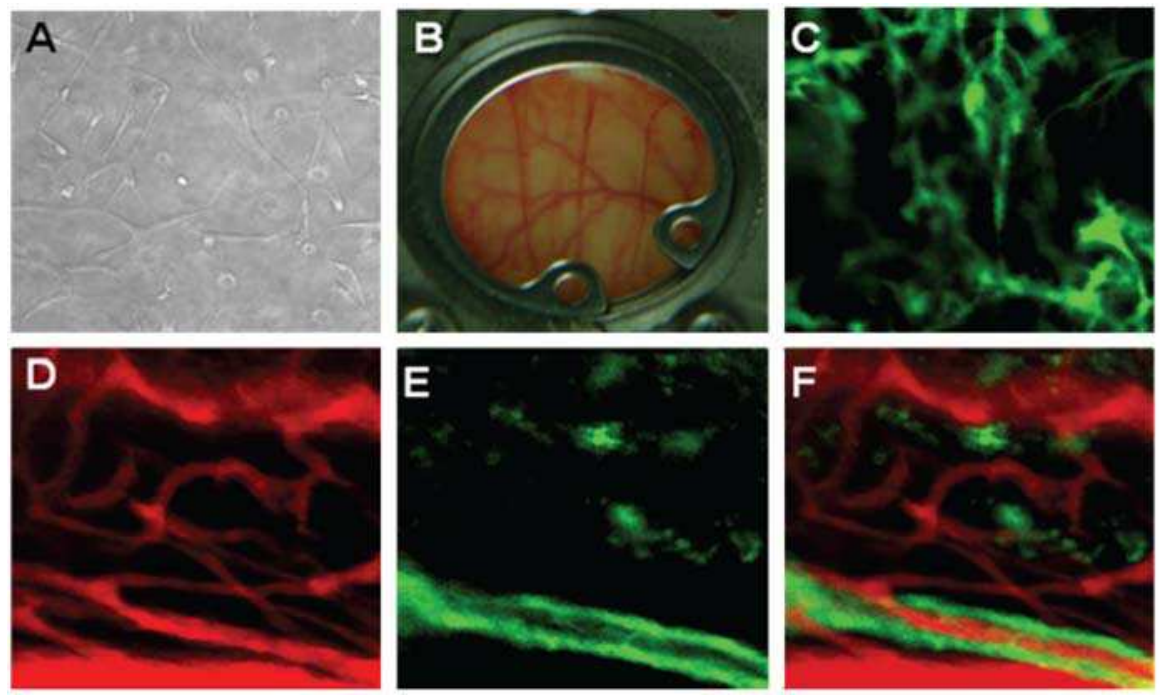

Fig. 11. Demonstration of functional vessels in vivo using Matrigel plug and dorsal window chamber. (A) Dorsal window chamber model in SCID mice. GFP+ hES-ECs were cultured in a mix of collagen and Matrigel for 1 day (left, upper panel), and implanted into dorsal windows in SCID mice (middle, upper panel). Images were taken at day 2,14 and 21 after implantation. After 14 days, Angiosense 680 was injected by tail vein to highlight perfused vessels within the dorsal window. Green, hES-ECs expressing GFP; red, functional blood vessels with contrast enhanced by Angiosense 680 
the dorsal skin fold windows in SCID mice. The titanium dorsal skin fold chamber (APJ Trading Co. Inc, Ventura, Ca) surgically mounted onto each mouse was described previously(Lehr et al., 1993). Briefly, mice were anesthetized with inhaled isoflurane (2\%$3 \%$ ), and two symmetrical titanium frames were implanted to sandwich the extended double layer of the skin. One layer was removed in a 10-mm-diameter circular area. The remaining layer, consisting of epidermis, subcutaneous tissue, and striated skin muscle, was covered with a glass coverslip incorporated in one of the titanium frames (Figure 11B). The animals were housed one per cage and had free access to water and food throughout the experiment. A recovery period of 2 days was allowed before the collagen/Matrigel patch was transplanted. Multiphoton laser-scanning intravital microscopy (IV-100, Olympus, Center Valley, PA) was used to visualize and quantify the morphological changes of EGFPexpressing hES-ECs.

To test whether the engineered vascular networks integrated with the host murine circulatory system, we next injected Angiosense 680 intravenously to enhance the contrast of perfused vessels. Importantly, several of the hES-EC derived vessels formed conduits that contained blood flow from day 12 to day 60 (Figure 11, D, E \& F). In summary, these data suggest that transplanted hES-ECs have angiogenic potential and are able to integrate into the host vasculature.

\section{Conclusion}

Taken together, the results showed that endothelial output efficiency was increased by a novel two-step differentiation of hES cells with collagen, and hES-ECs possess functional vasculogenic ability in vivo. However, the numbers surviving hES-ECs in infarcted tissue decreased significantly in the first few weeks and improved heart function at 2 weeks, but not to a significant degree later, demonstrating the requirement for long-term follow-up in all cardiac cell transplantation studies. Alternative transplantation protocols with larger numbers of hES-ECs, multiple grafts, or addition of matrix or prosurvival factors to prevent donor cell death after transplantation could eventually lead to the realization of further and sustained enhancement of heart function post myocardial infarction. These data suggest that prolonged heart function recovery may require more permanent graft survival of transplanted cells. In conclusion, two-step differentiation of hES cells can provide sufficient and functional endothelial cells for cell therapy, but exploring alternative transplant protocols that can improve cell survival and lead to sustained enhancement of heart function post infarction should be introduced in future. Furthermore, we believe molecular imaging will likely play a critical role in monitoring the localization and viability of these transplanted cells for cardiovascular diseases.

\section{Prospect}

Cardiovascular disease (CVD) accounts for approximately $30 \%$ of all deaths in the United States (Rosamond et al., 2008). Since CVD is primarily caused by endothelial dysfunction, therapeutic angiogenesis/vasculogenesis holds great promise for a potential cure. The logic behind angiogenesis/vasculogenesis is to improve the spontaneous healing process by supplementation of vascular progenitor cells or growth factors(Li et al., 2007). Endothelial progenitor cell transplantation can foster the formation of arterial collaterals and promote 
the regeneration of damaged tissues. Recently, human embryonic stem (hES) cells have generated much interest because of their capacity for self-renewal and pluripotency. In practical terms, hES cells can be cultured indefinitely ex vivo, and can differentiate into virtually any cell type in the adult body (Thomson et al., 1998, Reubinoff et al., 2000). hES cells are thus an attractive source for the derivation of large numbers of cells to be used in various tissue repair and cell replacement therapies. However, upon transplantation into living organisms, undifferentiated hES cells can spontaneously differentiate into rapidly proliferating teratomas, which are disordered amalgam of all three germs layers (Thomson et al., 1998, Reubinoff et al., 2000). Therefore, safely coaxing hES cells into committed progenitor lineages for therapeutic applications is an innovative and feasible strategy that can minimize the risk of cellular misbehavior and teratoma formation.

At present, hES cells are in the approval process for use in the treatment of neurodegenerative disease and Stargardt's Macular Dystrophy (SMD) by the Food and Drug Administration (FDA) of United States (Sun et al., 2010). The isolation of hESderived endothelial cells (hES-ECs) may also have potential therapeutic applications, including cell transplantation for repair of ischemic tissues and tissue-engineered vascular grafts. However, to fully understand the beneficial effects of stem cell therapy, investigators must be able to track the functional biology and physiology of transplanted cells in living subjects over time. At present, most cell therapy protocols are limited by their requirement for histological analysis to determine viable engraftment of the transplanted cells. The development of sensitive, noninvasive technologies to monitor this fundamental engraftment parameter will greatly aid clinical implementation of cell therapy. Moreover, recent research on hES-based therapy showed poor long-term engraftment of hES-ECs by serial bioluminescence imaging (Li et al., 2008). Thus, to sustain long-term engraftment of hES-ECs and realize the full benefits of hES-EC therapies, alternative transplantation protocols with addition of matrix (Cao et al., 2007) or pro-survival factors (Laflamme et al., 2007) to prevent cells death after transplantation must be developed.

\section{Acknowledgment}

This work was supported by grants from the National Key Scientific Program of China (2011CB964903) and National Natural Science Foundation of China (31071308)

\section{References}

Au, P., Daheron, L.M., Duda, D.G., Cohen, K.S., Tyrrell, J.A., Lanning, R.M., et al. (2008). Differential in vivo potential of endothelial progenitor cells from human umbilical cord blood and adult peripheral blood to form functional long-lasting vessels. Blood $111,1302-1305$.

Cao, F., Lin, S., Xie, X., Ray, P., Patel, M., Zhang, X., et al. (2006). In vivo visualization of embryonic stem cell survival, proliferation, and migration after cardiac delivery. Circulation 113, 1005-1014.

Cao, F., Sadrzadeh Rafie, A.H., Abilez, O.J., Wang, H., Blundo, J.T., Pruitt, B., et al. (2007). In vivo imaging and evaluation of different biomatrices for improvement of stem cell survival. Journal of tissue engineering and regenerative medicine 1, 465-468. 
Chen, T., Bai, H., Shao, Y., Arzigian, M., Janzen, V., Attar, E., et al. (2007). Stromal cellderived factor-1/CXCR4 signaling modifies the capillary-like organization of human embryonic stem cell-derived endothelium in vitro. Stem cells (Dayton, Ohio) 25, 392-401.

Chiu, R.C. (2003). Bone-marrow stem cells as a source for cell therapy. Heart failure reviews 8, 247-251.

Cho, S.W., Moon, S.H., Lee, S.H., Kang, S.W., Kim, J., Lim, J.M., et al. (2007). Improvement of Postnatal Neovascularization by Human Embryonic Stem Cell Derived Endothelial-Like Cell Transplantation in a Mouse Model of Hindlimb Ischemia. Circulation 116, 2409-19.

Efroni, S., Duttagupta, R., Cheng, J., Dehghani, H., Hoeppner, D.J., Dash, C., et al. (2008). Global transcription in pluripotent embryonic stem cells. Cell stem cell 2, 437-447.

Gerecht-Nir, S., Ziskind, A., Cohen, S. and Itskovitz-Eldor, J. (2003). Human embryonic stem cells as an in vitro model for human vascular development and the induction of vascular differentiation. Laboratory investigation 83, 1811-1820.

Kaufman, D.S., Hanson, E.T., Lewis, R.L., Auerbach, R. and Thomson, J.A. (2001). Hematopoietic colony-forming cells derived from human embryonic stem cells. Proceedings of the National Academy of Sciences of the United States of America 98, 10716-10721.

Kudo, T., Fukuchi, K., Annala, A.J., Chatziioannou, A.F., Allada, V., Dahlbom, M., et al. (2002). Noninvasive measurement of myocardial activity concentrations and perfusion defect sizes in rats with a new small-animal positron emission tomograph. Circulation 106, 118-123.

Laflamme, M.A., Chen, K.Y., Naumova, A.V., Muskheli, V., Fugate, J.A., Dupras, S.K., et al. (2007). Cardiomyocytes derived from human embryonic stem cells in pro-survival factors enhance function of infarcted rat hearts. Nature biotechnology 25, 1015-1024.

Lehr, H.A., Leunig, M., Menger, M.D., Nolte, D. and Messmer, K. (1993). Dorsal skinfold chamber technique for intravital microscopy in nude mice. The American journal of pathology 143, 1055-1062.

Levenberg, S., Golub, J.S., Amit, M., Itskovitz-Eldor, J. and Langer, R. (2002). Endothelial cells derived from human embryonic stem cells. Proceedings of the National Academy of Sciences of the United States of America 99, 4391-4396.

Li, Z., Han, Z. and Wu, J.C. (2009a). Transplantation of human embryonic stem cell-derived endothelial cells for vascular diseases. Journal of cellular biochemistry 106, 194-199.

Li, Z., Suzuki, Y., Huang, M., Cao, F., Xie, X., Connolly, A.J., et al. (2008). Comparison of reporter gene and iron particle labeling for tracking fate of human embryonic stem cells and differentiated endothelial cells in living subjects. Stem cells (Dayton, Ohio) 26, 864-873.

Li, Z., Wilson, K.D., Smith, B., Kraft, D.L., Jia, F., Huang, M., et al. (2009b). Functional and Transcriptional Characterization of Human Embryonic Stem Cell-Derived Endothelial Cells for Treatment of Myocardial Infarction. PLoS ONE 4, e8443.

Li, Z., Wu, J.C., Sheikh, A.Y., Kraft, D., Cao, F., Xie, X., et al. (2007). Differentiation, Survival, and Function of Embryonic Stem Cell Derived Endothelial Cells for Ischemic Heart Disease. Circulation 116, I-46-I-54. 
Li, Z.J., Wang, Z.Z., Zheng, Y.Z., Xu, B., Yang, R.C., Scadden, D.T. and Han, Z.C. (2005). Kinetic expression of platelet endothelial cell adhesion molecule-1 (PECAM1/CD31) during embryonic stem cell differentiation. J Cell Biochem 95, 559-570.

Lu, S.J., Feng, Q., Caballero, S., Chen, Y., Moore, M.A., Grant, M.B. and Lanza, R. (2007). Generation of functional hemangioblasts from human embryonic stem cells. Nat Methods 4, 501-9.

Reubinoff, B.E., Pera, M.F., Fong, C.-Y., Trounson, A. and Bongso, A. (2000). Embryonic stem cell lines from human blastocysts: somatic differentiation in vitro. Nat Biotech 18, 399-404.

Rosamond, W., Flegal, K., Furie, K., Go, A., Greenlund, K., Haase, N., et al. (2008). Heart disease and stroke statistics--2008 update: a report from the American Heart Association Statistics Committee and Stroke Statistics Subcommittee. Circulation 117, e25-146.

Schelbert, H.R., Inubushi, M. and Ross, R.S. (2003). PET imaging in small animals. J Nucl Cardiol 10, 513-520.

Sun, N., Longaker, M.T. and Wu, J.C. (2010). Human iPS cell-based therapy: Considerations before clinical applications. Cell Cycle 9, 880-5.

Thomson, J.A., Itskovitz-Eldor, J., Shapiro, S.S., Waknitz, M.A., Swiergiel, J.J., Marshall, V.S. and Jones, J.M. (1998). Embryonic stem cell lines derived from human blastocysts. Science 282, 1145-1147.

Thyagarajan, B., Liu, Y., Shin, S., Lakshmipathy, U., Scheyhing, K., Xue, H., et al. (2008). Creation of engineered human embryonic stem cell lines using phiC31 integrase. Stem cells (Dayton, Ohio) 26, 119-126.

Toyama, H., Ichise, M., Liow, J.S., Vines, D.C., Seneca, N.M., Modell, K.J., et al. (2004). Evaluation of anesthesia effects on [18F]FDG uptake in mouse brain and heart using small animal PET. Nuclear medicine and biology 31, 251-256.

van Laake, L.W., Passier, R., Monshouwer-Kloots, J., Verkleij, A.J., Lips, D.J., Freund, C., et al. (2007). Human embryonic stem cell-derived cardiomyocytes survive and mature in the mouse heart and transiently improve function after myocardial infarction Stem Cell Research 1, 9-24.

Vodyanik, M.A., Bork, J.A., Thomson, J.A. and Slukvin, II (2005). Human embryonic stem cell-derived CD34+ cells: efficient production in the coculture with OP9 stromal cells and analysis of lymphohematopoietic potential. Blood 105, 617-626.

Wang, Z.Z., Au, P., Chen, T., Shao, Y., Daheron, L.M., Bai, H., et al. (2007). Endothelial cells derived from human embryonic stem cells form durable blood vessels in vivo. Nature biotechnology 25, 317-318.

Wu, J.C., Cao, F., Dutta, S., Xie, X., Kim, E., Chungfat, N., et al. (2006a). Proteomic analysis of reporter genes for molecular imaging of transplanted embryonic stem cells. Proteomics 6, 6234-6249.

Wu, J.C., Spin, J.M., Cao, F., Lin, S., Xie, X., Gheysens, O., et al. (2006b). Transcriptional profiling of reporter genes used for molecular imaging of embryonic stem cell transplantation. Physiol Genomics 25, 29-38.

Wu, J.C., Tseng, J.R. and Gambhir, S.S. (2004). Molecular imaging of cardiovascular gene products. J Nucl Cardiol 11, 491-505. 
Xu, C., He, J.Q., Kamp, T.J., Police, S., Hao, X., O'Sullivan, C., et al. (2006). Human embryonic stem cell-derived cardiomyocytes can be maintained in defined medium without serum. Stem cells and development 15, 931-941.

Yamahara, K., Sone, M., Itoh, H., Yamashita, J.K., Yurugi-Kobayashi, T., Homma, K., et al. (2008). Augmentation of neovascularizaiton in hindlimb ischemia by combined transplantation of human embryonic stem cells-derived endothelial and mural cells. PLOS ONE 3, e1666.

Zhang, S.J. and $\mathrm{Wu}$, J.C. (2007). Comparison of imaging techniques for tracking cardiac stem cell therapy. J Nucl Med 48, 1916-1919. 


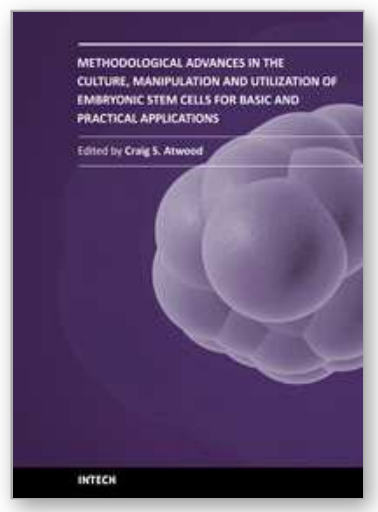

\author{
Methodological Advances in the Culture, Manipulation and \\ Utilization of Embryonic Stem Cells for Basic and Practical \\ Applications \\ Edited by Prof. Craig Atwood
}

ISBN 978-953-307-197-8

Hard cover, 506 pages

Publisher InTech

Published online 26, April, 2011

Published in print edition April, 2011

Pluripotent stem cells have the potential to revolutionise medicine, providing treatment options for a wide range of diseases and conditions that currently lack therapies or cures. This book describes methodological advances in the culture and manipulation of embryonic stem cells that will serve to bring this promise to practice.

\title{
How to reference
}

In order to correctly reference this scholarly work, feel free to copy and paste the following:

Yizhou Zheng, Deling Kong and Zongjin Li (2011). Non-invasive Imaging of Human Embryonic Stem Cells Derived Endothelial Cells Using Reporter Genes, Methodological Advances in the Culture, Manipulation and Utilization of Embryonic Stem Cells for Basic and Practical Applications, Prof. Craig Atwood (Ed.), ISBN: 978953-307-197-8, InTech, Available from: http://www.intechopen.com/books/methodological-advances-in-theculture-manipulation-and-utilization-of-embryonic-stem-cells-for-basic-and-practical-applications/non-invasiveimaging-of-human-embryonic-stem-cells-derived-endothelial-cells-using-reporter-genes

\section{INTECH}

open science | open minds

\section{InTech Europe}

University Campus STeP Ri

Slavka Krautzeka 83/A

51000 Rijeka, Croatia

Phone: +385 (51) 770447

Fax: +385 (51) 686166

www.intechopen.com

\section{InTech China}

Unit 405, Office Block, Hotel Equatorial Shanghai

No.65, Yan An Road (West), Shanghai, 200040, China

中国上海市延安西路65号上海国际贵都大饭店办公楼 405 单元

Phone: +86-21-62489820

Fax: +86-21-62489821 
(C) 2011 The Author(s). Licensee IntechOpen. This chapter is distributed under the terms of the Creative Commons Attribution-NonCommercialShareAlike-3.0 License, which permits use, distribution and reproduction for non-commercial purposes, provided the original is properly cited and derivative works building on this content are distributed under the same license. 